\title{
Investigation of Elemental Composition and Bonding Structure at the Sb-Doped $\mathrm{Ni}-\mathrm{FUSI} / \mathrm{SiO}_{2}$ Interface
}

\author{
N. Kawasaki, N. Sugiyama, Y. Otsuka, H. Hashimoto
}

Morphological Research Labolatory, Toray Reserch Center Inc, Otsu, Shiga 520-8567, Japan

In advanced CMOS devices, among many kinds of gate electrodes, fully silicide (FUSI) has an advantage because of controllable threshold voltage. It was proposed that dopants segregate at the silicide/gate dielectrics interface and the thin dopant pileup layer would modulate the threshold voltage of gate electrode [1]. The dopant pileup had been investigated by macroscopic techniques such as AES and SIMS, but these techniques provide no information on detailed elemental compositions and bonding structures at the interface. Here, we have investigated the structure at the interface between $\mathrm{Sb}$-doped Ni-FUSI gate electrode and $\mathrm{SiO}_{2}$ dielectrics by the high-spatial resolution techniques such as EDX and EELS in STEM. A poly-Si film deposited on $\mathrm{SiO}_{2}$ dielectric film was implanted with $\mathrm{Sb}$, followed by activation annealing. After $\mathrm{Ni}$ deposition on poly-Si, silicidation was processed using rapid thermal annealing. EDX and EELS analyses were performed on a JEM2100F (JEOL) operating at $200 \mathrm{kV}$.

Fig. 1 shows HAADF-STEM images at the $\mathrm{NiSi} / \mathrm{SiO}_{2}$ interface. We found characteristic two regions about $\mathrm{NiSi} / \mathrm{SiO}_{2}$ interface structure. In Fig. 1(a), thickness of $\mathrm{SiO}_{2}$ dielectrics was increased and thin high contrast layer was on $\mathrm{SiO}_{2}$. We found that this high contrast layer is not $\mathrm{Sb}$ segregation but Ni simple substance, by EDX and EELS analyses. On the contrary, in Fig. 1(b), we didn't found the phenomena as in the region (a). The phenomena found at region (a) were well explained as follows. Some of native oxide would remain at poly-Si surface before Ni deposition. The position of the residual oxide at the surface of poly-Si would move to Si-substrate side together with the consumption of poly-Si, finally arrive at $\mathrm{SiO}_{2}$ dielectric when NiSi formation was completed. Therefore, the thickness of $\mathrm{SiO}_{2}$ would seem to be increased. At the place where the residual oxide would arrive at $\mathrm{SiO}_{2}$ dielectric, the amount of Si supplied into NiSi side would be small, due to the lack of poly-Si and the increase of oxide layer. The amount of Ni diffused from Ni-rich silicide would be abundant, so $\mathrm{Ni}$ would exist as a simple substance without the reaction with $\mathrm{Si}$.

In the region (b), we could detect only $\mathrm{Sb}$ segregation at $\mathrm{NiSi} / \mathrm{SiO}_{2}$ interface. $\mathrm{Ni}-\mathrm{L}_{3}$ ELNES at the $\mathrm{Sb}$ segregation layer shows a very small shoulder around $862 \mathrm{eV}$, while the ELNES of NiSi has no shoulder at this energy (Fig. 2). This small shoulder could be seen in the theoretical ELNES calculated for $\mathrm{NiSb}$ (by first-principles band structure calculation, Wien2K code), where $\mathrm{Sb}$ was substituted for $\mathrm{Si}$ in MnP-type NiSi. Since the structure of NiSi above the Sb segregation layer is also the MnP-type structure, it is suggested that $\mathrm{Sb}$ at $\mathrm{NiSi} / \mathrm{SiO}_{2}$ interface would exist in NiSi crystal being substituted for Si atoms. In Fig. 3, we find a coupling of states at about 8-10eV in unoccupied $\mathrm{Ni} d$ and $\mathrm{Sb}$ d calculated density of states (DOS) of NiSb (dotted line in Fig. 3), corresponding to the position of the small shoulder in $\mathrm{Ni}-\mathrm{L}_{3}$ ELNES at $\mathrm{NiSi} / \mathrm{SiO}_{2}$, in the same way as $\mathrm{Ni}_{2} \mathrm{Si}$ reported in our previous study [2]. Therefore, it appears that the chemical bonding between $\mathrm{Ni}$ and $\mathrm{Sb}$ atoms in MnP-type NiSb structure has weak covalent character, which means that in the Sb segregation area at the bottom of Ni-FUSI, there is weak covalent bonding between $\mathrm{Ni}$ and $\mathrm{Sb}$ atoms. 


\section{References}

[1] W.P.Maszara, Journal of The Electrochemical Society. 152 (7) (2005) G550.

[2] N.Kawasaki et al., Ultramicroscopy. 108, (2008) 399.
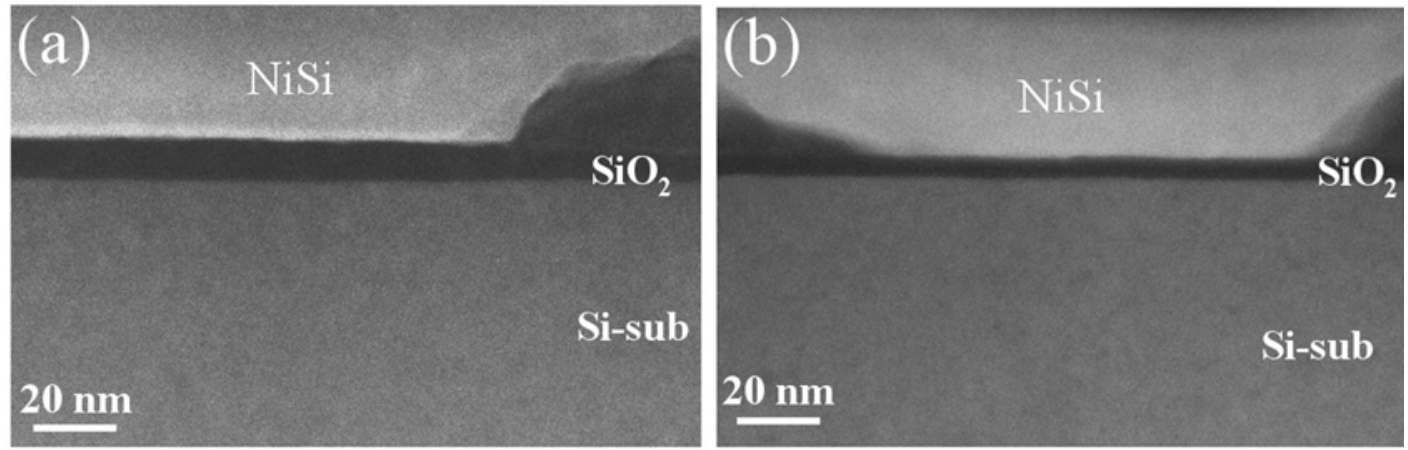

Fig. 1 HAADF-STEM images at $\mathrm{NiSi} / \mathrm{SiO}_{2}$ interface.

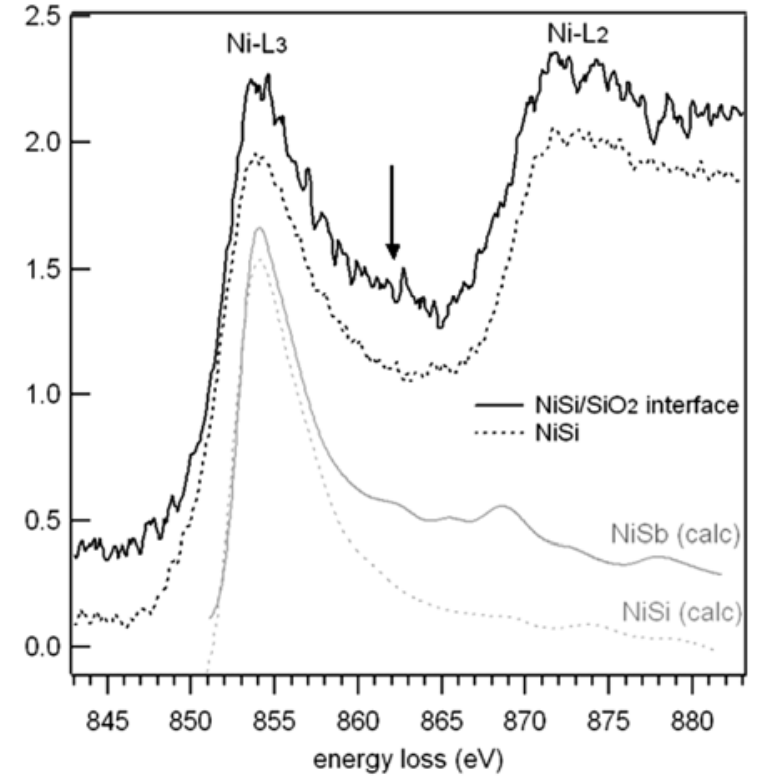

Fig. 2 Experimental Ni- $\mathrm{L}_{2,3}$ and theoretical Ni$\mathrm{L}_{3}$ ELNES at $\mathrm{NiSi} / \mathrm{SiO}_{2}$ interface in the region (b) and NiSi for comparison.

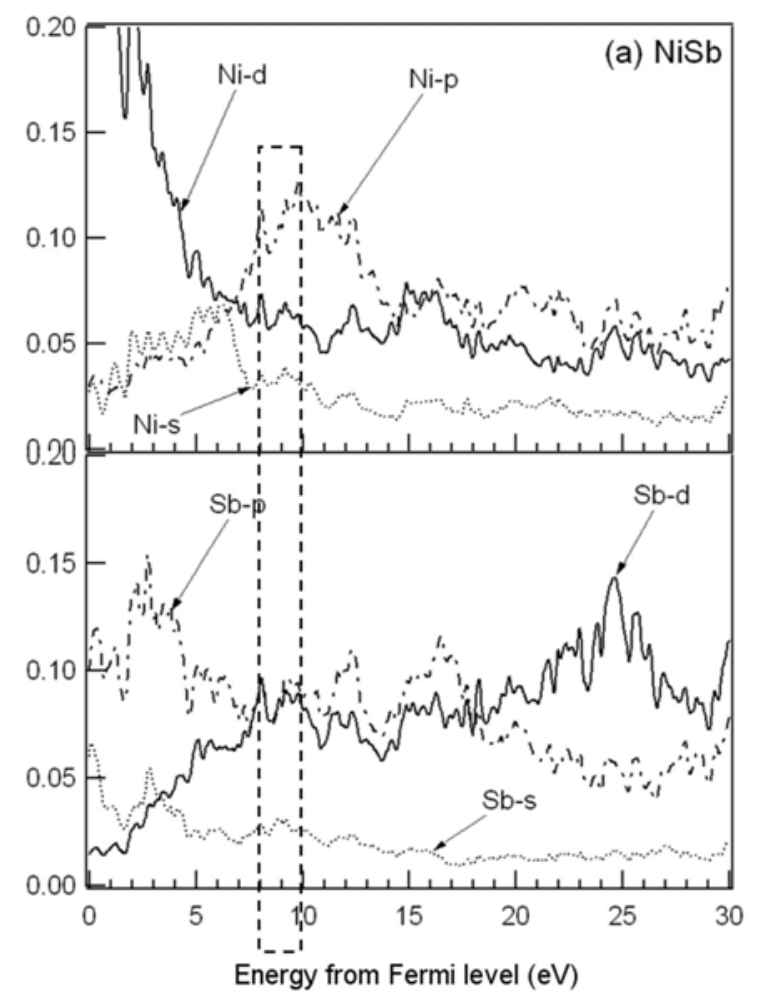

Fig. 3 Calculated unoccupied density of states (DOS) of MnP-type NiSb. 